\title{
Manual de inteligência emocional
}

\section{Claudia Cobêro}

Bar-on, R. \& Parker, J. D. A. (2002). Manual de inteligência emocional. Porto Alegre: ArtMed, 383 p.

Embora o termo "Inteligência Emocional" tenha crescido popularmente com a publicação do livro Inteligência Emocional de Daniel Goleman em 1995, esse construto já é alvo de muitas pesquisas desde a década de 90, quando os autores Salovey e Mayer definiram esse conceito pela primeira vez.

O livro Manual de Inteligência Emocional é dividido em quatro partes. A parte um aborda construtos básicos e é formada por sete capítulos; a parte dois, formada por seis capítulos, trata do desenvolvimento normal e anormal da inteligência emocional; a parte três, com quatro capítulos, abrange questões e métodos de avaliação; e a quarta e última parte discute as estratégias e intervenções de prevenção em cinco capítulos. O livro é composto, então, por 22 capítulos, escritos por autores ligados à prática e à pesquisa em Psicologia.

No primeiro capítulo, a autora Sabrina Zirkel aborda o conceito e as raízes históricas da inteligência social, fazendo, sobretudo, uma revisão da atual literatura psicológica da perspectiva da inteligência social. Para a autora, o modelo de inteligência social presume diferentes suposições básicas a respeito do comportamento humano, podendo ser proposital $e$ estratégico, quando orientado para a realização de algum objetivo. Pode ser também ativo, quando as pessoas interpretam ativamente o significado de seu ambiente social e as oportunidades e riscos apresentados. O comportamento pode ser também inerentemente social e contextualizado, tendo em vista que toda ação ocorre em um certo contexto cultural. É também evolutivo, dado o lugar e o estágio em que a pessoa se encontra no ciclo da vida e, por último, o comportamento pode ser cognitivo, visto que os esforços adaptativos das pessoas são criativos e imaginativos.

Já no Capítulo 2, os autores Keith Topping, William Bremner e Elizabeth A. Holmes discutem a evolução conceitual da competência social, bem como sua importância. Sua complexidade, segundo os autores, se dá pelo fato de estudos experimentais indicarem que a aprendizagem social seria uma função de diversas variáveis, entre as quais estariam os processos de atenção, retenção, reprodução motora e motivação.

No Capítulo 3, os autores Graeme J. Taylor e R. Michael Bagby abordam as bases históricas e as características clínicas do construto alexitimia. Discutem algumas semelhanças e diferenças entre a alexitimia, a inteligência emocional e outros construtos conceitualmente relacionados, bem como suas possíveis relações.

A psicóloga Carolyn Saarni, no Capítulo 4, discute o conceito de competência emocional e suas conseqüências à medida que essas capacidades emocionais são adquiridas. Ainda, a autora comenta sobre a distinção entre a competência emocional e o conceito de inteligência emocional.

No Capítulo 5, John D. Mayer, Peter Salovey e David R. discutem as diversas maneiras em que o termo inteligência emocional é usado. Explanam sobre três significados. O primeiro e mais amplo é uma acepção como zeitgeist, ou tendência intelectual cultural. Um segundo uso, mais popular, designa um grupo de traços de personalidade considerados importantes para se obter sucesso na vida. O terceiro e último significado foi adotado pelos autores na década de 90, quando pela primeira vez definiram o construto inteligência emocional; concebem-na como o conjunto de capacidades que dizem respeito ao processamento de informações emocionais.

Os autores Mary McCallum e William E. Piper, no Capítulo 6, exploram a disponibilidade psicológica e a inteligência emocional. Em um primeiro momento apresentam a definição do conceito de disponibilidade psicológica, sua relevância e medição. Em seguida, comparam-na com a inteligência emocional, abordando as dificuldades associadas à conceituação da disponibilidade psicológica.

No Capítulo 7, Jennifer Hedlund e Robert J. Sternberg fazem uma revisão da pesquisa em inteligência social, emocional e prática. Nessa revisão tentam responder se essas três inteligências são adequadamente caracterizadas como habilidades cognitivas ou, ainda, se podem ser desenvolvidas medidas confiáveis e válidas e se são conceitos distintos.

Richard D. Lane, no Capítulo 8, estuda as conexões entre a consciência emocional e a inteligência emocional, discutindo as dimensões psicológicas, neurobiológicas e sociais da consciência emocional. No capítulo seguinte, de número 9, escrito por Antonie Bechara, Daniel Tranel e Antonio R. Damásio, abordamse os progressos no entendimento do papel da emoção na cognição, visto que ela desempenha o importante papel de influenciar muitas de nossas funções cognitivas e comportamentais, incluindo a memória e a

E-mail: claudiacobero@zipmail.com.br 
tomada de decisões.

No Capítulo 10, Robert J. Sternberg e Elena L. Grigorenko revisam a literatura e o desenvolvimento da inteligência prática. Estabelecem comparações entre as trajetórias evolutivas da inteligência acadêmica e da inteligência prática, as quais, segundo os autores do capítulo, apresentam trajetórias bastante distintas.

A autora Elaine Scharfe, no Capítulo 11, faz uma síntese da literatura evolutiva recente, examinando o desenvolvimento da expressão, do entendimento e da regulação das emoções em bebês e crianças jovens. Enfatiza, ainda, a competência no mundo emocional das crianças associada a habilidades sociais superiores e à aceitação dos amigos.

O capítulo 12, escrito por Robert R. McCrae, descreve o perfil da personalidade da pessoa hipoteticamente inteligente do ponto de vista emocional, na perspectiva do modelo dos cinco grandes fatores. O autor aborda algumas implicações do conceito de inteligência emocional, valendo-se do conhecimento a respeito das características da personalidade.

James R. Averill discute no capítulo 13 o conceito de inteligência e as capacidades que a compõe. Busca, nesse capítulo, a relação da inteligência com outras aptidões humanas importantes, principalmente as relacionadas com a emoção e a criatividade.

Nos capítulos subseqüentes 14, 15, 16 e 17, os autores abrangem as questões e métodos de avaliação. Assim, no capítulo 14, discutem-se medidas de autoavaliação e avaliação por meio de um observador da alexitimia. Já no Capítulo 15, o foco é a medida para a inteligência emocional, defendendo as escalas de aptidão e abordando alguns dos instrumentos já existentes, como o MEIS e o MSCEIT. O relato da história e do desenvolvimento é feito no Capítulo 16, bem como dos resultados preliminares do Emotional Competence Inventory (ECI), um novo teste de inteligência emocional baseado no modelo de competências. No Capítulo 17, o autor Reuven Bar-on descreve idéias a respeito da inteligência social e emocional, levantadas com a aplicação do Emotional Quocient Inventory (EQ-i) em inúmeros estudos conduzido no mundo, durante os últimos 17 anos. Descreve também o desenvolvimento e as propriedades psicométricas do EQ-i.

Os Capítulos 18 e 19 abordam as estratégias e intervenções de prevenção nas escolas. No Capítulo 18 são discutidos os critérios para avaliar a qualidade de programas escolares de aprendizagem social e emocional, enquanto o Capítulo 19 trata da eficácia dos programas escolares para a promoção da competência social. Ainda nesse capítulo, é apresentada uma visão geral de mais de 700 relatórios de pesquisas de avaliação dos resultados de programas escolares para aumentar a competência social.

No Capítulo 20, Cary Cherniss aborda a competência social e emocional no local de trabalho, discutindo a longa história de tentativas para ajudar os trabalhadores a aumentar sua inteligência emocional.

Os autores Gerald Mattheus e Moshie Zeidner abordam, no Capítulo 21, o sucesso do enfrentamento em situações de estresse e relacionam o estresse com a inteligência emocional. Os autores exploram perspectivas para defender a inteligência emocional como um novo conceito explicativo na pesquisa do estresse.

Para finalizar o livro, o autor James D. A. Parker, no Capítulo 22, discute brevemente as implicações clínicas e terapêuticas do conceito de inteligência emocional. Aborda, também a psicoterapia para clientes alexitímicos e a terapia em grupo.

O livro Manual de Inteligência Emocional (2002) é um livro bem abrangente e destinado a profissionais interessados na área da inteligência emocional. Os autores participantes foram eficazes e claros ao descrever o assunto, colaborando para torná-lo um livro de grande valia para pesquisadores da área, dando uma visão global do construto e de suas implicações em diversos contextos. É um livro mais acadêmico, baseado em pesquisas, com rigor científico, podendo ser considerado o primeiro livro acadêmico base sobre a inteligência emocional, ao contrário do livro de Goleman que é um livro popular.

Sobre a autora:

Claudia Cobêro é psicóloga e mestranda do Programa de Mestrado de Psicologia da Universidade São Francisco. 